\title{
Mechanical and Acoustic Performance Prediction Model for Elastomers in
}

\section{Different Environmental Conditions}

\author{
Yunke Huang, ${ }^{1}$ Also at 2 Hong Hou, ${ }^{1, a)}$ Selda Oterkus, ${ }^{2}$ Zhengyu Wei, ${ }^{1}$ and Shuai Zhang ${ }^{1}$ \\ ${ }^{1}$ Department of Environmental Engineering, School of marine science and technology, Northwestern \\ Polytechnical University, 127 West Youyi Road, Beilin District, Xi'an, Shaanxi,710072, P.R.China \\ ${ }^{2}$ Department of Naval Architecture, Ocean \& Marine Engineering, University of Strathclyde, 100 \\ Montrose Street, Glasgow, G4 OLZ, UK
}

Electronic mail: houhong@nwpu.edu.cn

\begin{abstract}
This study focuses on the constitutive model including temperature and pressure effects to investigate the dynamic, mechanical and acoustic properties of elastomers in frequency domain under different underwater conditions. The developed constitutive relation is based on Harvriliak-Negami (H-N) model by implementing experimental Young's modulus data and by using Williams-Landel-Ferry (WLF) shift function for relaxation time calculation. The H-N model accurately captures the dynamic mechanical modulus for wide range of frequencies for constant temperature and pressure based on measured DMTA (dynamic mechanical thermal analysis) data. Since the WLF shift function is related with the relaxation time for different temperatures and pressures, the proposed model represents a simple and accurate prediction of dynamic modulus for varying external conditions. Relationship between Young's modulus and acoustic properties of the rubber structure can be established by investigating the hydro-wave propagation process. The predictions from the proposed model are verified by comparing with mechanical and acoustic experimental data at different temperatures and pressures. Additionally, the parametric study is conducted to investigate the effect of $\mathrm{H}-\mathrm{N}$ parameters on mechanical and acoustic properties of elastomer materials. The proposed model can be used to predict the mechanical and acoustic properties in different environmental conditions accurately.
\end{abstract}

Keywords: Mechanical parameter, Sound absorption, H-N model, Temperature and pressure

\section{I . INTRODUCTION}

Elastomer materials with large internal friction and good damping capabilities are able to effectively absorb incident acoustic energy, thus usually being utilized as underwater anechoic tile for acoustic insulation. ${ }^{1}$ Due to the viscoelasticity of elastomers, the acoustic performance depends on the temperature, pressure, and frequency. Currently, the broad-band acoustic performance of elastomers in different external conditions is difficult to implement by laboratory methods and in-situ measurements, especially in low-frequency range.

Acoustic performance of elastomers can be predicted based on dynamic mechanical response in different underwater environmental conditions. ${ }^{2}$ Constitutive models are implemented to describe the mechanical response of elastomers. Generalized Kelvin model and Maxwell liquid model are usually used to calculate frequency-dependent mechanical properties, such as the storage modulus and the loss factor. ${ }^{3}$ The viscoelastic fractional relaxation models have better contribution to dynamic response measurements, ${ }^{4,5}$ hence the generalized high-order models such as Kelvin-Voigt model and Zener model have been widely developed and applied. ${ }^{5,6}$ Besides, the measuring techniques for dynamic mechanical properties are investigated by using different techniques. Linear viscoelastic modulus of complex fluids can be obtained by optical 
measurement based on generalized Langevin equation for Brownian motion. ${ }^{7}$ Nanoindentation on viscoelastic material is another advanced technique involving displacement data from nano indenter. The test data is used to obtain viscoelastic modulus properties as a function of frequency. ${ }^{8}$ The nano indentation continuous stiffness measurement technique based on hereditary integral operator develops complex viscoelastic modulus functions with better accuracy compared to conventional data from DMTA. ${ }^{9}$ Flat punch nanoindentation is another technique to measure the complex modulus of linear viscoelastic solid in relatively lower frequency range $(0.01-50 \mathrm{~Hz}){ }^{10}$ Those measured data must be representative of steady-state harmonic motion and linear viscoelasticity under constant temperature and pressure.

The numerical master curve for mechanical response can be fit by Sigmoidal function, ${ }^{11}$ but it cannot provide high accuracy in some frequency range. Havriliak-Negami model shows an empirical function for the dynamic mechanical response of viscoelastic materials, ${ }^{12}$ accurately describing the mechanical behaviors in frequency domain. Jeffrey et al. proposed a numerical curve-fitting method to analysis DMTA data, ${ }^{13}$ which can be described by $\mathrm{H}-\mathrm{N}$ model. ${ }^{14}$ The $\mathrm{H}-\mathrm{N}$ model is established by determining four temperature-independent parameters and one temperature-dependent parameter. Furthermore the mechanical parameters in wide frequency range can be obtained by using $\mathrm{H}-\mathrm{N}$ model. The curve-fitting method for $\mathrm{H}-$ $\mathrm{N}$ model is then improved by Dong Hao et al. ${ }^{15}$ and validated by carbon black filled rubbers. Parameter identification method for $\mathrm{H}-\mathrm{N}$ model are widely utilized in mechanical analysis of viscoelastic materials, such as asphalt concretes, ${ }^{16,17,18,19}$ epoxy $\operatorname{composites}^{20}$ and multifunctional viscoelastic structure. ${ }^{21}$ Effect of frequency and temperature on dynamic mechanical parameters and the identification process for $\mathrm{H}-\mathrm{N}$ constants are considered by previous researchers. ${ }^{22,23}$

The researchers also investigate the acoustic properties for elastomers for various structures. 24,25,26 Elastomers have the characteristics of both elastic solid and viscous fluid. Therefore, microscopic chains of elastomers always cause acoustic energy loss by internal friction and resonance 27,28 which are affected by temperature and pressure especially for underwater conditions. Underwater acoustic measurement methods have been developed to determine the absorption and transmission performance of polymers, and relevant test systems have been established. ${ }^{29}$ Impulse method and transfer function method for acoustic measurement in waterfilled tubes are comparatively sophisticated, and have been improved by many researchers. ${ }^{30,31}$ Free field method, which is similar to real underwater conditions, is usually implemented in in-situ tests, but measurement accuracy of the method needs to be improved. ${ }^{32,33}$ Underwater acoustic response is also simulated numerically by Fulei Zhou et al. ${ }^{34}$ They established acoustic tube by using COMSOL solid mechanical and acoustic module, in which the absorption boundary is simulated by using PML. ${ }^{35}$ Another numerical method to calculate the acoustic performance of elastomers is by inversing mechanical parameters such as bulk and shear modulus. These parameters are used to find reflection and absorption coefficient via mathematical models. ${ }^{36,37,38}$ However the acoustic boundary is not taken into account in this method.

In this study, mechanical and acoustic performance of elastomers in different temperatures and pressures are investigated. Frequency dependent viscoelastic material model is suggested for more realistic underwater conditions. In the proposed model, a fitting method for $\mathrm{H}-\mathrm{N}$ parameters for a wide range of frequency is used. Direct calculation of relaxation time from improved WLF shift equation which considers both temperature and pressure effect is developed. Furthermore, the developed model can be used to predict absorption performance based on the relation between acoustic and mechanical performance. The sensitivity analysis for H-N parameters provides better basis for practical application of elastomer structures for different underwater conditions. The proposed model is easy to implement to DMTA data for a single test condition. The verification of the proposed model is shown by comparing with the 
experimental data.

\section{II . THE ESTABLISHMENT AND APPLICATIONS OF H-N TEMPERATURE- PRESSURE MODEL}

Viscoelastic H-N model builds a relation between complex modulus, rubbery modulus and glassy modulus. The normal expression of H-N model can be represented as ${ }^{6}$

$$
E^{*}(\omega, \tau)=\frac{E_{0}-E_{\infty}}{\left[1+(i \omega \tau)^{\alpha}\right]^{\beta}}+E_{\infty}
$$

where $E^{*}$ is the complex modulus, $E_{0}$ is the rubbery modulus in low frequency stage, $E_{\infty}$ is the glassy modulus in high frequency stage, $\alpha$ is the parameter related with loss peak width, $\beta$ is the parameter related with loss peak symmetry, and $\tau$ is the relaxation time. It should be noted that the parameters $E_{0}, E_{\infty}, \alpha, \beta$ are independent of environmental conditions, on the other hand the parameter $\tau$ depends on temperature and pressure field.

The complex modulus can be described by the storage modulus $E^{\prime}$ and the loss modulus $E^{\prime \prime}$ as

with

$$
E^{*}=E^{\prime}+i E^{\prime \prime}
$$

$$
\begin{gathered}
E^{\prime}=\operatorname{real}\left(E^{*}\right)=E_{\infty}+\frac{\left(E_{0}-E_{\infty}\right) \cos (\beta \theta)}{\left[1+2(\omega \tau)^{\alpha} \cos (\alpha \pi / 2)+(\omega \tau)^{2 \alpha}\right]^{\beta / 2}} \\
E^{\prime \prime}=\operatorname{imag}\left(E^{*}\right)=\frac{\left(E_{\infty}-E_{0}\right) \sin (\beta \theta)}{\left[1+2(\omega \tau)^{\alpha} \cos (\alpha \pi / 2)+(\omega \tau)^{2 \alpha}\right]^{\beta / 2}}
\end{gathered}
$$

The relation between storage modulus $E^{\prime}$ and the loss modulus $E^{\prime \prime}$ are defined through loss factor, $\tan \delta$ as

$$
\tan \delta=\frac{E^{\prime \prime}}{E^{\prime}}=\frac{\left(E_{\infty}-E_{0}\right) \sin (\beta \theta)}{E_{\infty}\left[1+2(\omega \tau)^{\alpha} \cos (\alpha \tau / 2)+(\omega \tau)^{2 \alpha}\right]^{\beta / 2}+\left(E_{0}-E_{\infty}\right) \cos (\beta \theta)}
$$

in which $\theta=\arctan \frac{(\omega \tau)^{\alpha} \sin (\alpha \pi / 2)}{1+(\omega \tau)^{\alpha} \cos (\alpha \pi / 2)}$.

\section{A. The calibration of viscoelastic $\mathrm{H}-\mathrm{N}$ model}

The relation between the storage modulus and the loss factor can be represented by the Wicket figure ${ }^{39}$ based on the thermal rheological properties of elastomers. By using Eqs. (3-5) the loss factor as a function of storage modulus for elastomer is represented in Fig. 1 . The Wicket curve for elastomer is obtained by using $E_{0}=1 \mathrm{MPa}, E_{\infty}=3 \mathrm{MPa}$ and $\alpha=\beta=0.5$. As it can be seen, the shape of the Wicket figure is same for different relaxation times. This is also observed by previous researchers. ${ }^{13,22}$ 


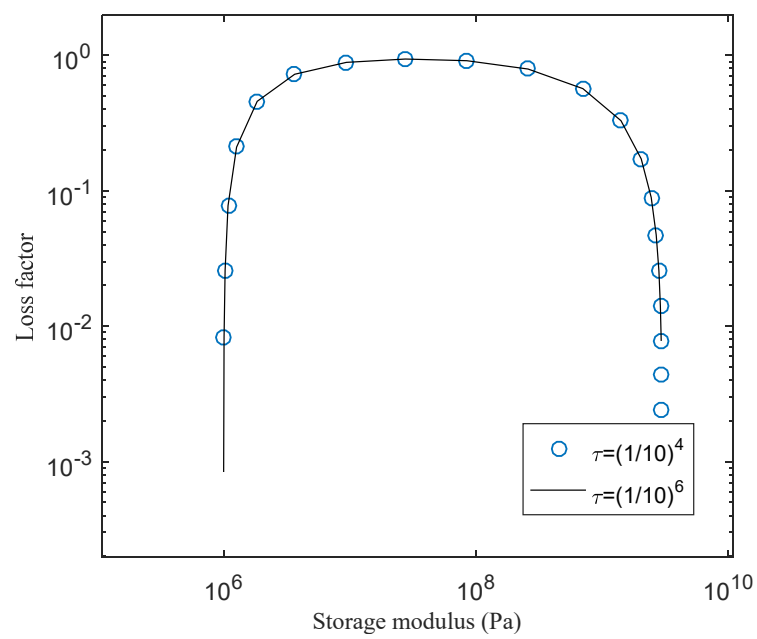

Fig. 1 Wicket figure for viscoelastic material in different relaxation times.

The Wicket curve can be used for determining four environment-independent parameters. In DMTA experiment, loss modulus, $E^{\prime \prime}$ and loss factor, $\tan \delta$ are measured as a function of frequency. The calculated complex modulus is also obtained based on the initial values for $\mathrm{H}$ $\mathrm{N}$ parameters $E_{0}, E_{\infty}, \alpha, \beta$ with $\tau=1$. The optimized values of $\mathrm{H}-\mathrm{N}$ parameters can be determined based on Levenberg-Marquardt method by using MATLAB optimization toolbox.

According to Levenberg-Marquardt method, new $\mathrm{H}-\mathrm{N}$ parameters are estimated in a range specified values at each iteration as $10^{-4}$ for parameter $\alpha, \beta$ and $10^{2}$ for parameter $E_{0}, E_{\infty}$. The convergence criteria are specified based on Wicket and Cole-Cole error formulas ${ }^{40}$ as

$$
\begin{gathered}
F_{1}=\frac{\sum_{f}\left|E_{\text {mea }}^{\prime \prime}-E_{\text {cal }}^{\prime \prime}\right|^{2}}{\sum_{f}\left|E_{\text {mea }}^{\prime \prime}\right|^{2}} \\
F_{2}=\frac{\sum_{f}\left|\log \left(\tan \delta_{\text {mea }}\right)-\log \left(\tan \delta_{\text {cal }}\right)\right|^{2}}{\sum_{f}\left|\log \left(\tan \delta_{\text {mea }}\right)\right|^{2}}
\end{gathered}
$$

in which $F_{1}$ represents the Wicket error formula and $F_{2}$ represents the Cole-Cole error formula ${ }^{40}$. $E_{\text {mea }}^{\prime \prime}$ and $E_{c a l}^{\prime \prime}$ represent the measured and calculated loss modulus, respectively. $\tan \delta_{\text {mea }}$ and $\tan \delta_{\text {cal }}$ represent the measured and calculated loss factor, respectively. The convergence tolerations are specified as $10^{2}$ for objective function $F_{1}$ and $10^{-4}$ for objective function $F_{2}$. The procedure for Levenberg-Marquardt method can be summarized in Fig.2

Table I. Basic relative properties of elastomer specimens

\begin{tabular}{ccccc}
\hline $\begin{array}{c}\text { Relative } \\
\text { properties }\end{array}$ & $\begin{array}{c}\text { Tensile } \\
\text { strength } \\
(\mathrm{MPa})\end{array}$ & $\begin{array}{c}\text { Tear strength } \\
(\mathrm{N} / \mathrm{cm})\end{array}$ & $\begin{array}{c}\text { Hardness (Shore } \\
\mathrm{A})\end{array}$ & $\begin{array}{c}\text { Strain energy } \\
\text { release rate } \\
\left(\mathrm{kJ} / \mathrm{m}^{2}\right)\end{array}$ \\
\hline $\begin{array}{c}\text { chloroprene } \\
\text { rubber }\end{array}$ & 0.89 & 21 & 71.5 & 6.69 \\
$\begin{array}{c}\text { specimen } \\
\text { neoprene } \\
\text { rubber } \\
\text { specimen }\end{array}$ & 1.19 & 32 & 73.5 & 2.07 \\
\hline
\end{tabular}




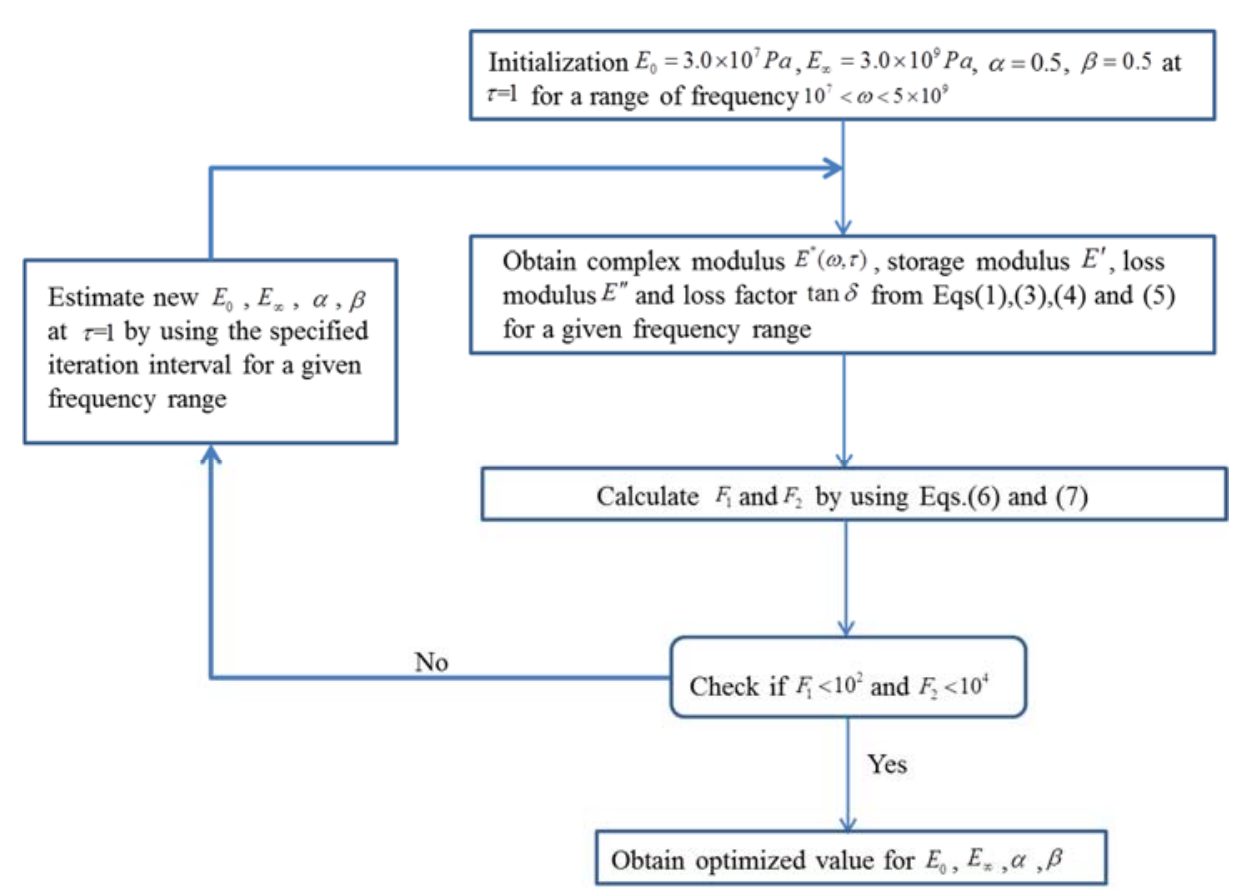

Fig. 2 Flow chart for Levenberg-Marquardt method to obtain H-N parameters.

After finding the H-N parameters, the expression for relaxation time, $\tau$ can be calculated by using Eq.(1) for given complex Young's modulus $E^{*}(\omega)$ as ${ }^{13}$

$$
\tau=-i \exp \frac{\left\{\log \left(\exp \left(\log \left(\left(E_{0}-E_{\infty}\right) /\left(E^{*}-E_{\infty}\right)\right) / \beta\right)-1\right) / \alpha\right\}}{\omega}
$$

During DMTA tests, a solid cylinder chloroprene rubber specimen with the diameter of $114.8 \mathrm{~mm}$, the height of $48.6 \mathrm{~mm}$ and mass density of $1463.1 \mathrm{~kg} / \mathrm{m}^{3}$ is used. Relative tensile and mechanical properties of the chloroprene rubber specimen have been provided in Table I. The DMTA data for storage modulus and the loss factor are obtained at different frequency points under $20^{\circ} \mathrm{C}$ and room-pressure. Table II shows the initial and optimized values of $E_{0}, E_{\infty}, \alpha$, $\beta$. Substituting the optimized H-N parameters into Eq. (3) and (5) the Wicket curve is obtained. Fig. 3 represents the Wicket curve and its comparison with the experimental data. As it can be seen from the comparison, the model predicts the experimental data very well.

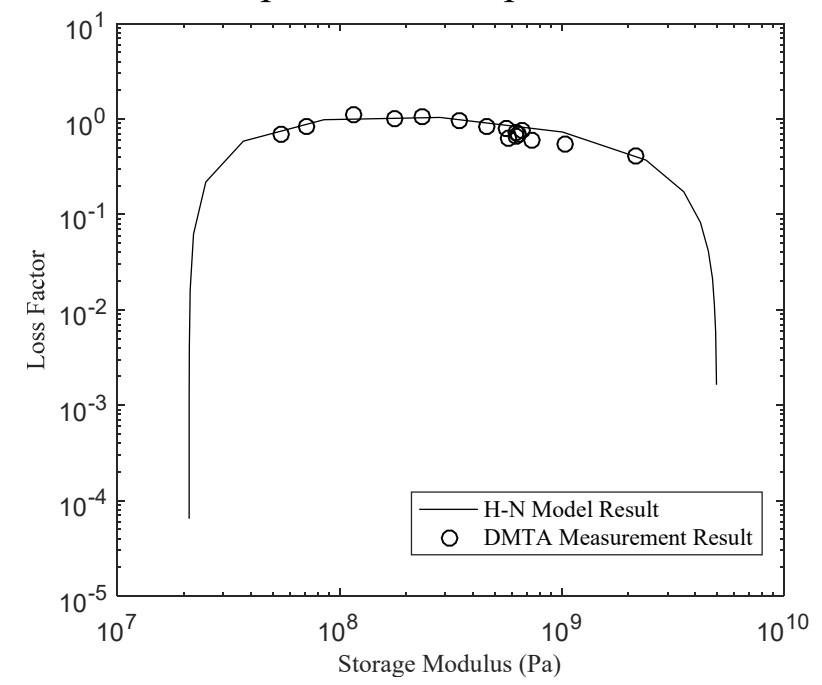

Fig. 3 Wicket figure comparison of $\mathrm{H}-\mathrm{N}$ model and DMTA measuring data. 
The mechanical master curves for storage modulus and loss factor are expanded into continuous frequency range based on H-N model in Eq. (3) and (5). Fig. 4 shows that DMTA data fits very well with the master curves. The H-N broadband model can be easily expanded to fit DMTA data.

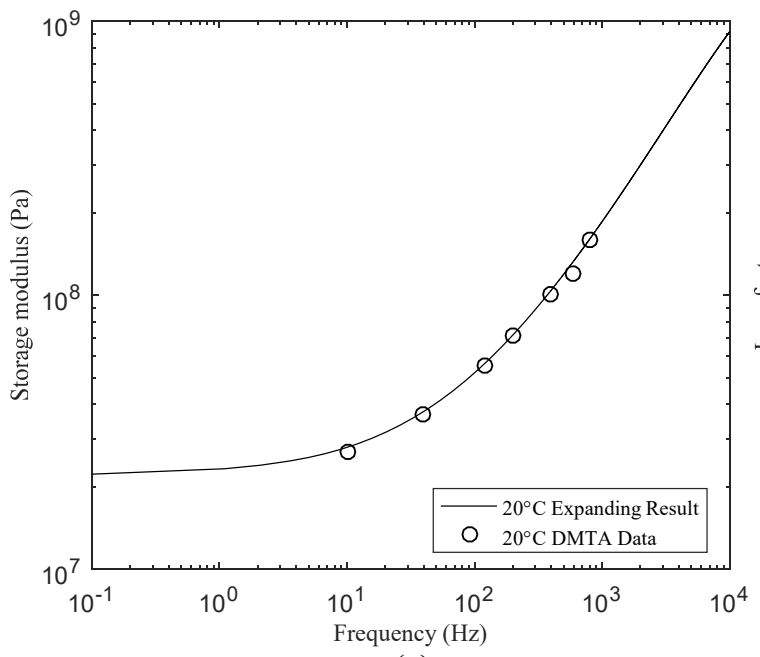

(a)

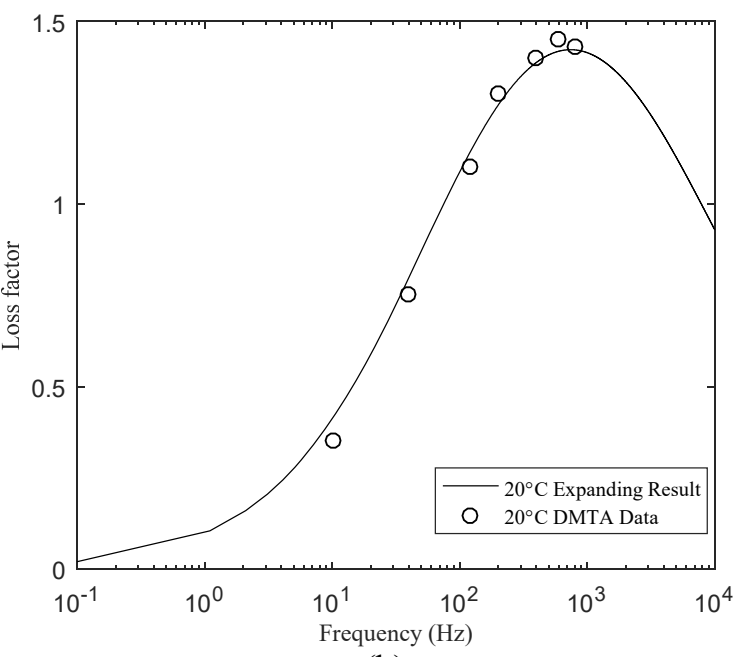

(b)

Fig. 4 Mechanical parameter expansion in $0-10 \mathrm{kHz}$ frequency range by $\mathrm{H}-\mathrm{N}$ model. (a) the storage modulus in $20^{\circ} \mathrm{C}$ (b) the loss factor in $20^{\circ} \mathrm{C}$.

\section{B. The improvement of WLF shift function}

By using WLF (Williams-Landel-Ferry) shift function, the effect of temperature from $T_{0}$ to $T$ on H-N parameters will be included by modifying the relaxation time, $\tau$ as

$$
\log \phi_{T}=\log \left(\frac{\tau}{\tau_{0}}\right)=\frac{-C_{1}\left(T-T_{0}\right)}{C_{2}+\left(T-T_{0}\right)}
$$

in which $\phi_{T}$ is the temperature transfer factor; $T_{0}$ is the reference temperature; $\tau$ and $\tau_{0}$ are the relaxation times corresponding to $T$ and $T_{0}$, respectively. $C_{1}$ and $C_{2}$ in Eq. (9) are empirical parameters related to thermal expansion coefficient, only depending on the reference temperature, $T_{0}$.

If the reference temperature $T_{0}$ is chosen as glass-transient temperature, the approximate values of empirical $C_{1}$ and $C_{2}$ parameters are provided by Williams, ${ }^{41}$ otherwise these parameters need to be recalculated. The empirical parameters are recalculated based on new reference temperature. It is assumed that the previous reference temperature is glass-transient temperature, $T_{0}$ and the new reference temperature is $T_{M}=T_{0}+\Delta T$. The empirical parameters $C_{1}^{\prime}$ and $C_{2}^{\prime}$ with respect to $T_{M}$ are obtained as ${ }^{42}$

$$
\left\{\begin{array}{l}
C_{1}^{\prime}=\frac{C_{1} C_{2}}{C_{2}+\Delta T} \\
C_{2}^{\prime}=C_{2}+\Delta T
\end{array}\right.
$$

It is worth noting that the empirical parameters in WLF shift function can be transformed with respect to reference temperatures. The values of $C_{1}^{\prime}, C_{2}^{\prime}$ for the different reference temperatures, $T_{M}$ can be calculated by using Eq. (10) in which $C_{1}, C_{2}$ are determined at a certain reference temperature $T_{0}$ (such as glass-transient temperature $T_{g}$ ).

Additionally, pressure has also significant effect on the mechanical properties of elastomers. 
This phenomenon has been well explained by Losi and Knauss. ${ }^{43}$ It is based on the free-volume theory of elastomers. The higher pressure leads to the less available free volume, which means the thermal response of the elastomer is much closer to that at the glass transition temperature. The transfer factor in Eq. (9) can be modified by including the effect of pressure, $P$ and temperature, $T$ as

$$
\log \phi_{T, P}=\frac{-C_{1}^{\prime}\left(T-T_{M}-\theta(P)\right)}{C_{2}^{\prime}+T-T_{M}-\theta(P)}
$$

where $T_{M}$ is the reference temperature; $C_{1}^{\prime}, C_{2}^{\prime}$ are the empirical parameters at temperature $T_{M}$.

\section{The establishment of $\mathrm{H}-\mathrm{N}$ temperature pressure model}

The thermal response of the elastomer highly depends on temperature and pressure. Based on DMTA data of the storage modulus and the loss factor at constant temperature $T_{M}$ and pressure $P_{M}\left(P_{M}\right.$ is usually specified as room-pressure), the relaxation time $\tau\left(T_{M}, P_{M}\right)$ in this condition can be calculated by using Eq. (8).

The relaxation time $\tau(T, P)$ for different temperatures and pressures can be determined by

$$
\tau(T, P)=\tau\left(T_{M}, P_{M}\right) \phi_{T, P}
$$

in which $\phi_{T, P}$ is the transfer factor from $\left(T_{M}, P_{M}\right)$ to $(T, P)$.

Similarly, the storage modulus for different temperatures and pressures can be obtained by modifying the relaxation time $\tau$ as

$$
E^{*}[\omega, \tau(T, P)]=E^{*}\left[\omega, \tau\left(T_{M}, P_{M}\right) \phi_{T, P}\right]
$$

The effect of pressure on glass-transient temperature can be expressed as ${ }^{43}$

$$
T_{(g, P)}=T_{g}+\kappa \times \Delta P
$$

in which $T_{(g, P)}$ is the glass-transient temperature at pressure $P$, and $T_{g}$ is the glass-transient temperature at room-pressure. Generally, $\kappa=0.25 \mathrm{~K} / \mathrm{MPa}^{43}$ for most rubber-like material. Therefore, Eq. (14) becomes

$$
T_{(g, P)}=T_{g}+0.25 \times \Delta P
$$

According to WLF equation, the transfer factor, $\phi_{T_{g}, p}$ for environmental condition $(T, P)$ can be determined by following equation

$$
\log \phi_{T_{g}, p}=\frac{C_{1}\left(T-T_{(g, P)}\right)}{C_{2}+\left(T-T_{(g, P)}\right)}=\frac{C_{1}\left(T-T_{g}-0.25 \times \Delta P\right)}{C_{2}+\left(T-T_{g}-0.25 \times \Delta P\right)}
$$

in which $C_{1}$ and $C_{2}$ are empirical parameters at temperature $T_{g}$. On the other hand, if the DMTA measurement temperature $T_{M}$ is chosen as the reference temperature, the transfer factor, $\phi_{T_{M}, p}$ for environmental condition $(T, P)$ becomes

$$
\log \phi_{T_{M}, p}=\frac{C_{1}^{\prime}\left(T-T_{M}-0.25 \times \Delta P\right)}{C_{2}^{\prime}+\left(T-T_{M}-0.25 \times \Delta P\right)}
$$

Here $C_{1}^{\prime}$ and $C_{2}^{\prime}$ are empirical parameters at temperature $T_{M}$ and can be evaluated by Eq. (10), since the effect of pressure on WLF empirical parameters is ignorable. Hence, the H-N temperature-pressure model for any environmental condition $(T, P)$ can be derived based on the mechanical response under the condition $\left(T_{M}, P_{M}\right)$ as 


$$
E^{*}(\omega, \tau(T, P))=E^{*}\left[\omega, \tau\left(T_{M}, P_{M}\right) 10^{-\frac{C_{1}^{\prime}\left(T-T_{M}-0.25^{*} \Delta P\right)}{C_{2}^{\prime}+\left(T-T_{M}-0.25^{*} \Delta P\right)}}\right]
$$

\section{RELATION OF MECHANICAL AND ACOUSTIC PERFORMANCE}

\section{A. The relation of physical parameters and mechanical properties}

The relation between complex Young's modulus and loss angle $\theta$ can be represented as

$$
E^{*}=E(\cos \theta+i \sin \theta)
$$

where $\rho$ is the material density, $c$ is the wave speed amplitude and $E=\rho c^{2}$ is the amplitude of complex Young's modulus. The storage modulus represents the real part of complex Young's modulus as

$$
E^{\prime}=\rho c^{2} \cos \theta
$$

Therefore, the longitude wave velocity can be determined as

$$
c=\sqrt{E^{\prime} /(\rho \cdot \cos \theta)}
$$

The complex wave number can be represented in terms of wave frequency, complex Young's modulus and material density as ${ }^{44}$

$$
\begin{aligned}
k & =\omega\left(\frac{\rho}{E^{*}}\right)^{1 / 2}=\omega\left(\frac{\rho}{E(\cos \theta+i \sin \theta)}\right) \\
& =\omega\left(\frac{\rho}{E}\right)^{1 / 2}\left[\cos \left(\frac{\theta}{2}\right)-i \sin \left(\frac{\theta}{2}\right)\right] \\
& =k^{\prime}-i \beta
\end{aligned}
$$

where $\beta$ is the attenuation coefficient and it can be defined as

$$
\beta=\omega\left(\frac{\rho \cos \theta}{E^{\prime}}\right)^{1 / 2} \cdot \sin \frac{\theta}{2}
$$

\section{B. The relation of physical parameters and acoustic performance}

Fig. 5 represents the acoustic performance test by water-filled tube. During the test, the elastomer specimen is placed in the terminal of the water-filled tube.

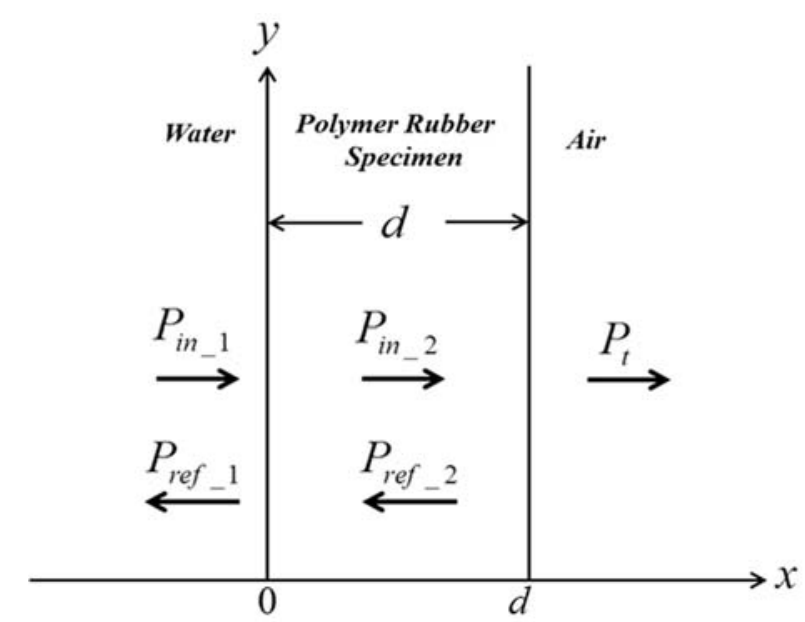

Fig. 5 Wave propagation process in elastomer specimen.

In order to get a relation between the physical parameters and acoustic performance, it is 
assumed that the specimen, water and air are semi-infinite and homogeneous media. It is also considered that the plane sound wave is incident toward the specimen surface through the water. The characteristic impedance of the water can be expressed as $Z_{1}=\rho_{\text {water }} \cdot c_{\text {water }}=1.480 \times 10^{6} \mathrm{~Pa} \cdot \mathrm{s} / \mathrm{m}^{3}$, the characteristic impedance of the elastomer specimen is $Z_{2}=\rho_{\text {specimen }} \cdot c_{\text {specimen }}$ and the characteristic impedance of the air is $Z_{3}=\rho_{\text {air }} \cdot c_{\text {air }}=415 \mathrm{~Pa} \cdot \mathrm{s} / \mathrm{m}^{3}$, respectively.

After multi-reflection and transmission between front and rear layers of the specimen, the internal spatial sound pressure $P_{2}$, the particle vibration velocity, $v_{2}$ and the input impedance $Z_{2 \text { in }}$ of the specimen can be represented as ${ }^{45}$

$$
\begin{aligned}
P_{2} & =p_{2} \cdot e^{i \omega t}=\left(A e^{-i k z}+B e^{i k z}\right) \cdot e^{i \omega t} \\
v_{2} & =-\frac{1}{\rho} \int \frac{\partial P_{2}}{\partial z} d t=-\frac{1}{i \omega \rho} \cdot \frac{\partial p_{2}}{\partial t} \cdot e^{i \omega t} \\
& =-\frac{k}{\omega \rho}\left(B e^{i k z}-A e^{-i k z}\right) \cdot e^{i \omega t} \\
Z_{2 i n} & =\left.\frac{p_{2}(x)}{v_{2}(x)}\right|_{x=0}=\frac{Z_{2}(A+B)}{A-B}=Z_{2} \cdot \frac{1+\frac{B}{A}}{1-\frac{B}{A}}
\end{aligned}
$$

According to sound pressure and impedance continuity criteria at the interface at $x=0$, the complex coefficients of sound reflection and transmission are determined as ${ }^{45}$

$$
\begin{aligned}
& r=\frac{Z_{2}\left(Z_{3}-Z_{1}\right) \cos k d+i\left(Z_{2}^{2}-Z_{1} Z_{3}\right) \sin k d}{Z_{2}\left(Z_{3}+Z_{1}\right) \cos k d+i\left(Z_{2}^{2}+Z_{1} Z_{3}\right) \sin k d} \\
& t=\frac{2 Z_{2} Z_{3}}{Z_{2}\left(Z_{1}+Z_{3}\right) \cos k d+i\left(Z_{2}^{2}+Z_{1} Z_{3}\right) \sin k d}
\end{aligned}
$$

Finally, acoustic absorption coefficient can be expressed as ${ }^{45}$

$$
a=1-r^{2}-t^{2}
$$

\section{THE PERFORMANCE PREDICTION RESULT FOR AN ELASTOMER SPECIMEN}

\section{A. The mechanical and acoustic performance prediction in different external condition}

A neoprene rubber specimen with the diameter of $118.2 \mathrm{~mm}$ and the thickness of $45.1 \mathrm{~mm}$ is used in mechanical and acoustic experiments. The specimen is fabricated by periodically arraying conical air cavities in the neoprene rubber matrix with lattice constant $a=34.55 \mathrm{~mm}$ as shown in Fig 6. The air cavities in the specimen have diameter of $20.0 \mathrm{~mm}$, height of $30.0 \mathrm{~mm}$ and the tip angle of $18.5^{\circ}$. The mass density of neoprene rubber is $1457.9 \mathrm{~kg} / \mathrm{m}^{3}$. Relative tensile and mechanical properties of the neoprene rubber specimen have been provided in Table I. 


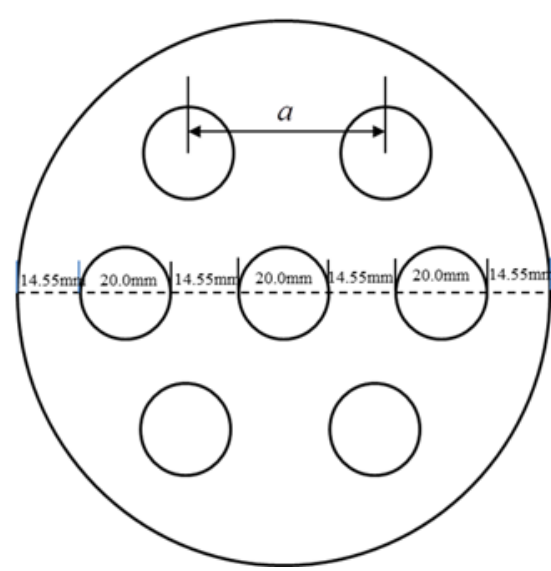

(a)

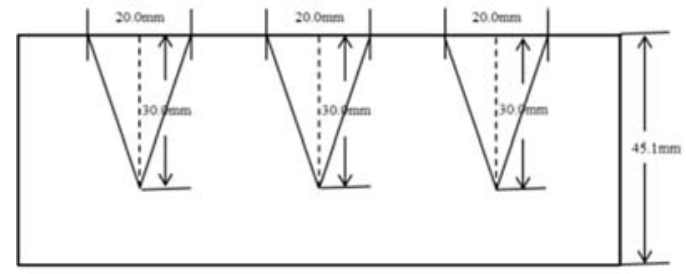

(b)

Fig. 6 Schematic diagram of the specimen B: (a) the structure of the specimen with periodical air cavities in the neoprene rubber, (b) the cross section of the specimen.

The storage modulus, the loss factor and the absorption coefficient data are obtained at roompressure and at various temperatures: $10^{\circ} \mathrm{C}, 20^{\circ} \mathrm{C}, 30^{\circ} \mathrm{C}, 40^{\circ} \mathrm{C}$. The storage modulus and loss factor are measured by DMTA experiment, while absorption coefficient is measured by waterfilled tube experiment using transfer function method. ${ }^{46}$

The H-N model is established based on the DMTA data including storage modulus and loss factor measured at $20^{\circ} \mathrm{C}$ and at room-pressure. The $\mathrm{H}-\mathrm{N}$ parameters are obtained by using MATLAB optimization toolbox as described in Section II. A. Table II summarizes the initial and optimized values of four environment-independent parameters. The relaxation time for this environmental condition is derived by using Eq. (8). After calculating the H-N parameters, the empirical parameters for WLF shift function are calculated by using Eq. (10) as $C_{1}^{\prime}=21.3$ and $C_{2}^{\prime}=42.3$

Table II. Initial values and optimized values of model parameters

\begin{tabular}{cccccc}
\hline & Parameter & $E_{0}(\mathrm{~Pa})$ & $E_{\infty}(\mathrm{Pa})$ & $\alpha$ & $\beta$ \\
\hline $\begin{array}{c}\text { chloroprene } \\
\text { rubber }\end{array}$ & Initial Value & $3.0 \times 10^{7}$ & $3.0 \times 10^{9}$ & 0.5 & 0.5 \\
Oppecimen & Value & $2.118 \times 10^{7}$ & $4.806 \times 10^{9}$ & 0.711 & 0.462 \\
\hline $\begin{array}{c}\text { neoprene } \\
\text { rubber } \\
\text { specimen }\end{array}$ & $\begin{array}{c}\text { Initial Value } \\
\text { Optimized }\end{array}$ & $3.395 \times 10^{7}$ & $6.292 \times 10^{8}$ & 0.288 & 0.628 \\
\hline
\end{tabular}

Based on H-N temperature-pressure model described in Section II.C, the storage modulus is calculated by using Eq. (18), loss factor is calculated by using Eq. (5) and absorption coefficient is calculated by using Eq. (29). The predicted and measured mechanical and acoustic properties as a function of frequency as presented in Fig. 7-9. As it can be seen from the results, the proposed model predicts the experimental results very well. 


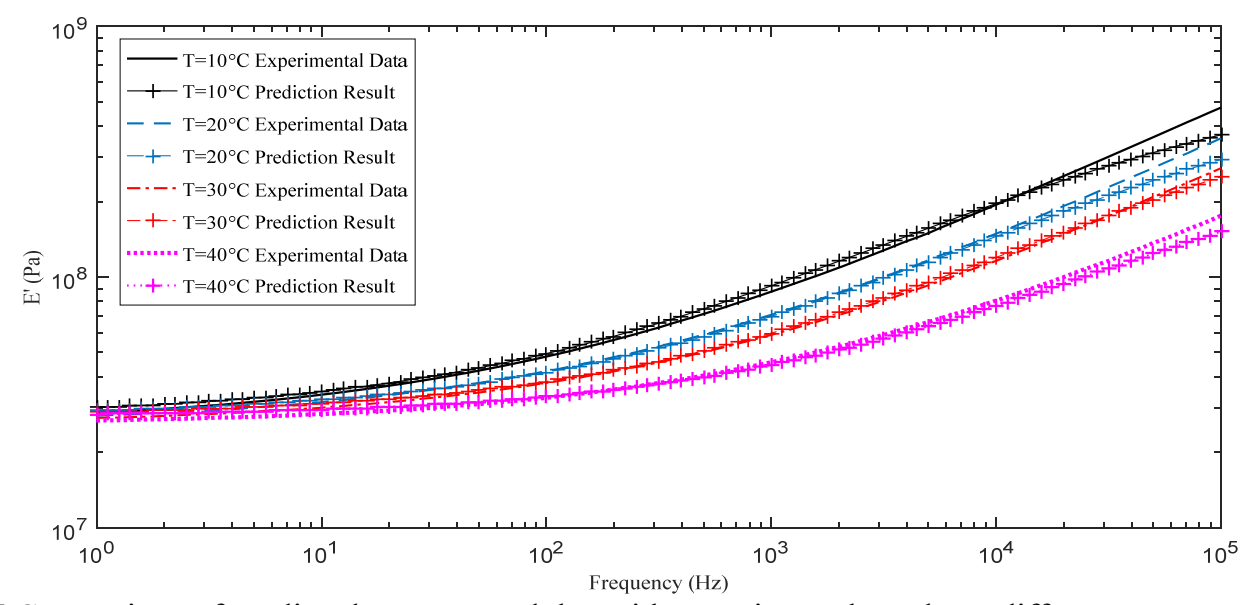

Fig. 7 Comparison of predicted storage modulus with experimental results at different temperatures. (color online)

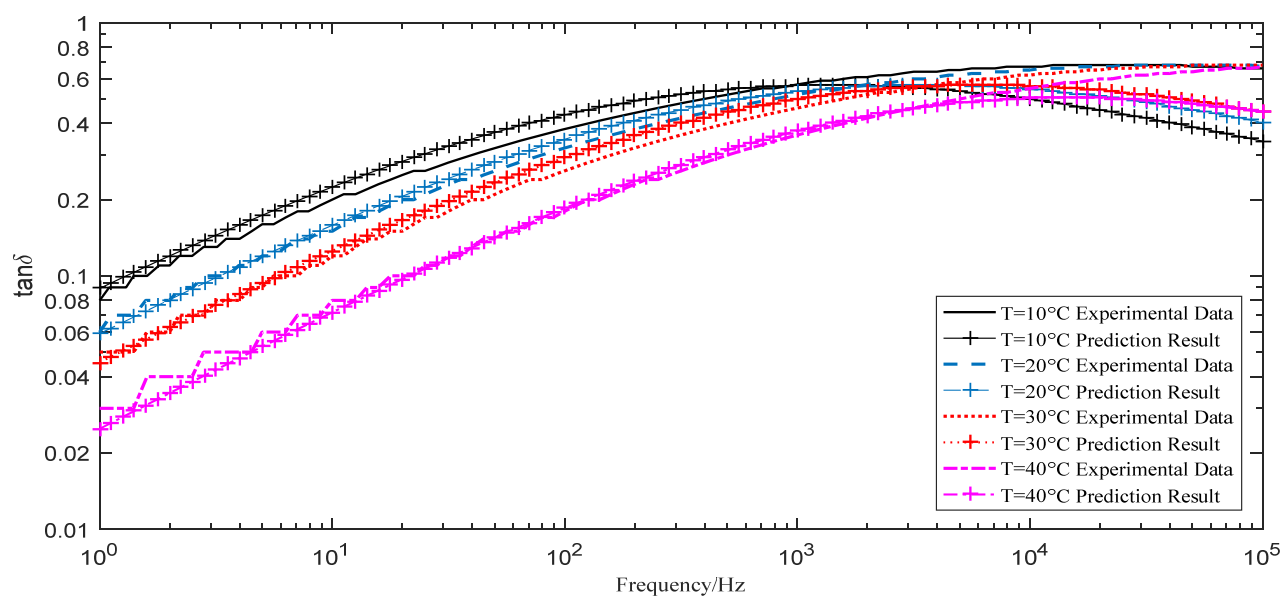

Fig. 8 Comparison of predicted loss factor with experimental results at different temperatures. (color online)

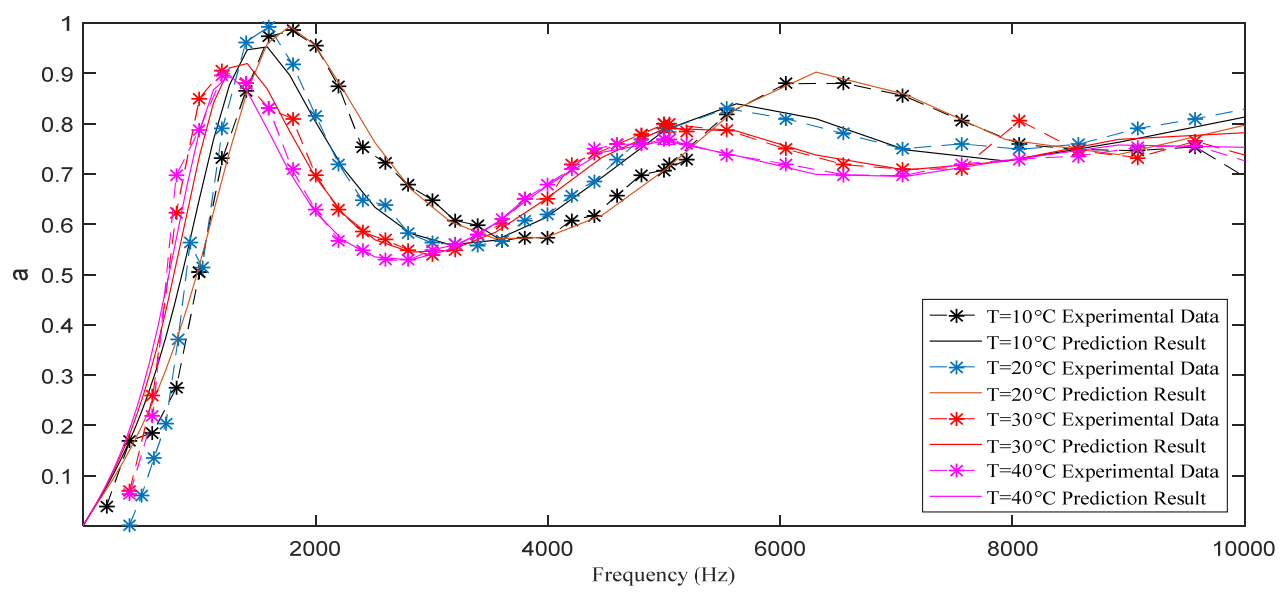

Fig. 9 Comparison of predicted sound absorption with experimental results at different temperatures. (color

online)

As it can be seen from Fig. 7, the predicted storage modulus compares very well with the experimental measurements. The maximum deviation between the predicted and experimental data, observed at $10^{5} \mathrm{~Hz}$ at $10^{\circ} \mathrm{C}$, is $6.7 \%$. On the other hand, for higher temperatures, the maximum deviation decreases down to $3.4 \%$.

Similarly, as it can be seen from Fig. 8, in high frequency range, the maximum deviation 
between the predicted and experimental data for loss factor decreases from $10.5 \%$ to $2.8 \%$ with the increasing of temperature. On the other hand, in low frequency range below $50 \mathrm{~Hz}$, the maximum deviation between the predicted and experimental data for loss factor remain $13 \%$ for each temperature condition. It is also observed that the measured loss factor data are slightly larger than the model predictions in all frequency range.

For the sound absorption coefficient, model prediction represented by solid lines cover the whole frequency range from $1-10 \mathrm{kHz}$ with similar absorption values of 0.00145 in the origin points for different temperatures, while the experimental results represented by dash lines with stars are discretized data which are obtained at $200 \mathrm{~Hz}$ for $10^{\circ} \mathrm{C}$ and $400 \mathrm{~Hz}$ for $20^{\circ} \mathrm{C}, 30^{\circ} \mathrm{C}$ and $40^{\circ} \mathrm{C}$ respectively. As it can be seen in Fig. 9, the sound absorption coefficients predicted by the model are in good agreement with measurement data, especially near the absorption peak below $3 \mathrm{kHz}$. In the frequency range above $4 \mathrm{kHz}$, there is still a good agreement between predicted and measured data at $10^{\circ} \mathrm{C}$ and $20^{\circ} \mathrm{C}$. On the other hand, maximum deviation between the predicted and experimental data is $15 \%$ for $30^{\circ} \mathrm{C}$ and $40^{\circ} \mathrm{C}$. As it can be observed from the figure, the measured data shows instabilities at these temperatures. Two absorption peaks are observed at around frequencies $2000 \mathrm{~Hz}$ and $5500 \mathrm{~Hz}$. The air cavities in the structure cause the friction between the air and neoprene rubber. As a result, two modes of absorption peaks appear in the observed frequency range. The absorption peak slightly moves to the low frequency range and the amplitude decreases as the temperature increases.

Furthermore, the mechanical and acoustic responses of the specimen in wide frequency domain at pressure range $0 \mathrm{MPa}-30 \mathrm{MPa}$ with interval of $10 \mathrm{MPa}$ and temperature range $0^{\circ} \mathrm{C}$ $40^{\circ} \mathrm{C}$ with interval of $10^{\circ} \mathrm{C}$ have been predicted by using the proposed model. As shown in Fig. 10-12. the storage modulus, loss factor and sound absorption depend on temperature and pressure. As the temperature decreases, storage modulus increases as shown in Fig.10, and increasing rate of storage modulus is larger in lower pressures.

Meanwhile, the loss peak moves towards low frequency range in higher pressures and lower temperatures as shown in Fig.11. As for absorption coefficient shown in Fig. 12, pressure rise leads to absorption coefficient drop, which is more significant in lower temperatures. Those characteristics are identical to the neoprene rubber performance in practical applications.

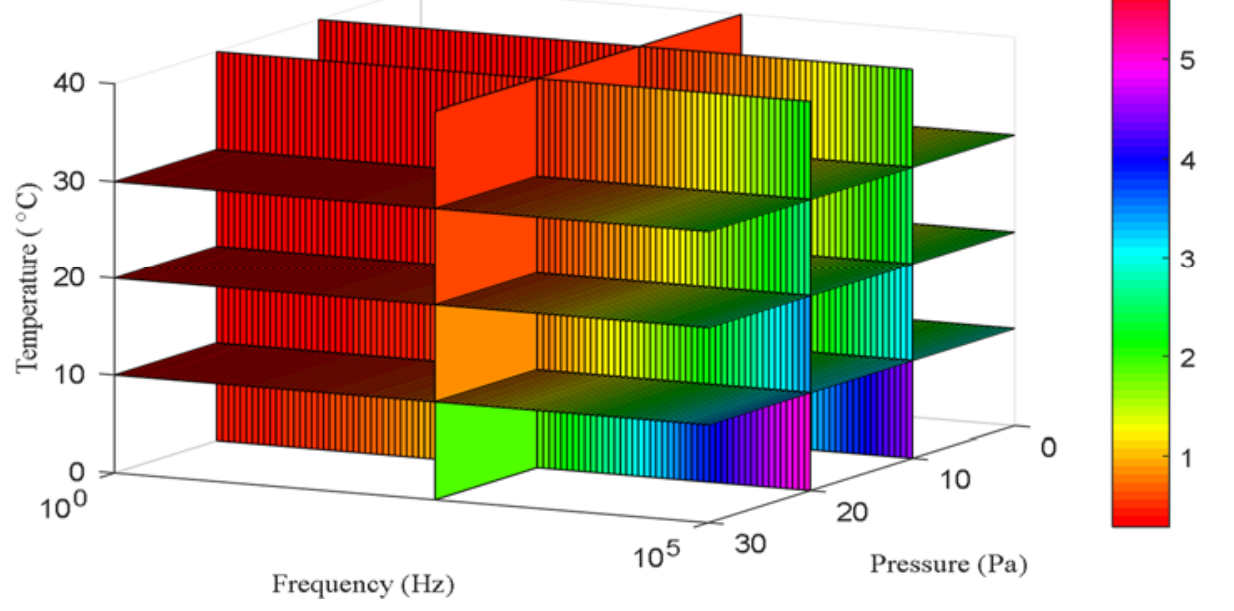

Fig. 10 Prediction of storage modulus at a range of temperature and pressure. (color online) 


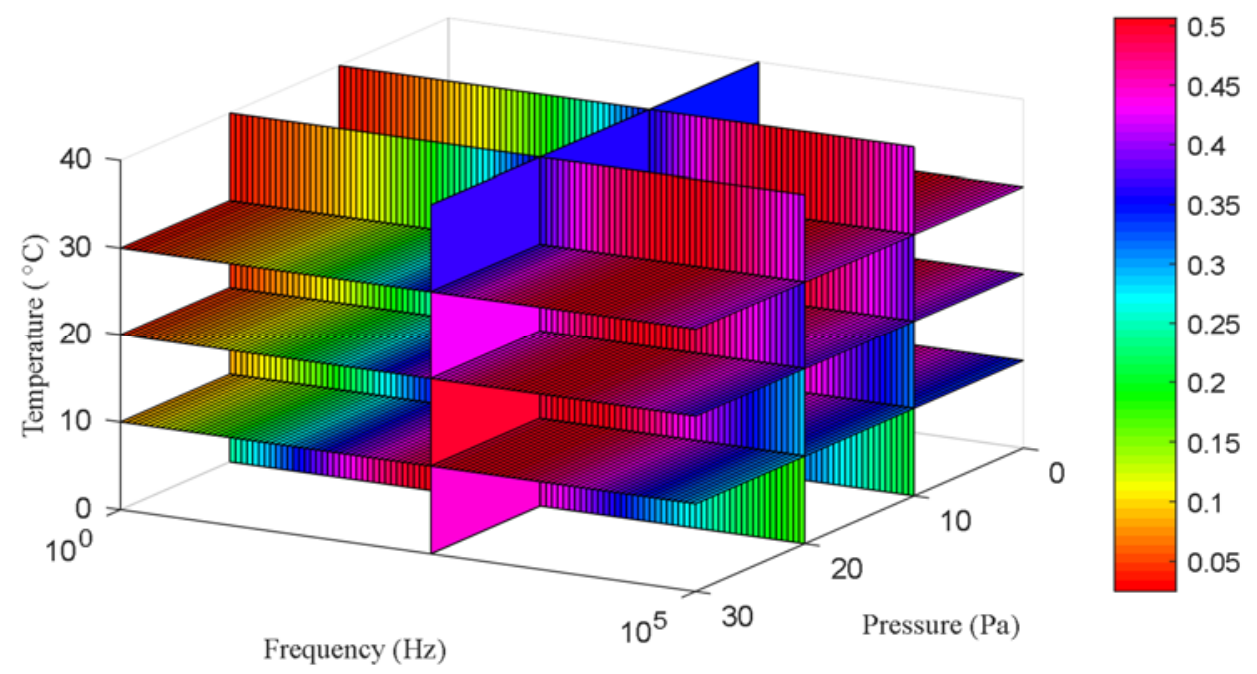

Fig. 11 Prediction of loss factor at a range of temperature and pressure. (color online)

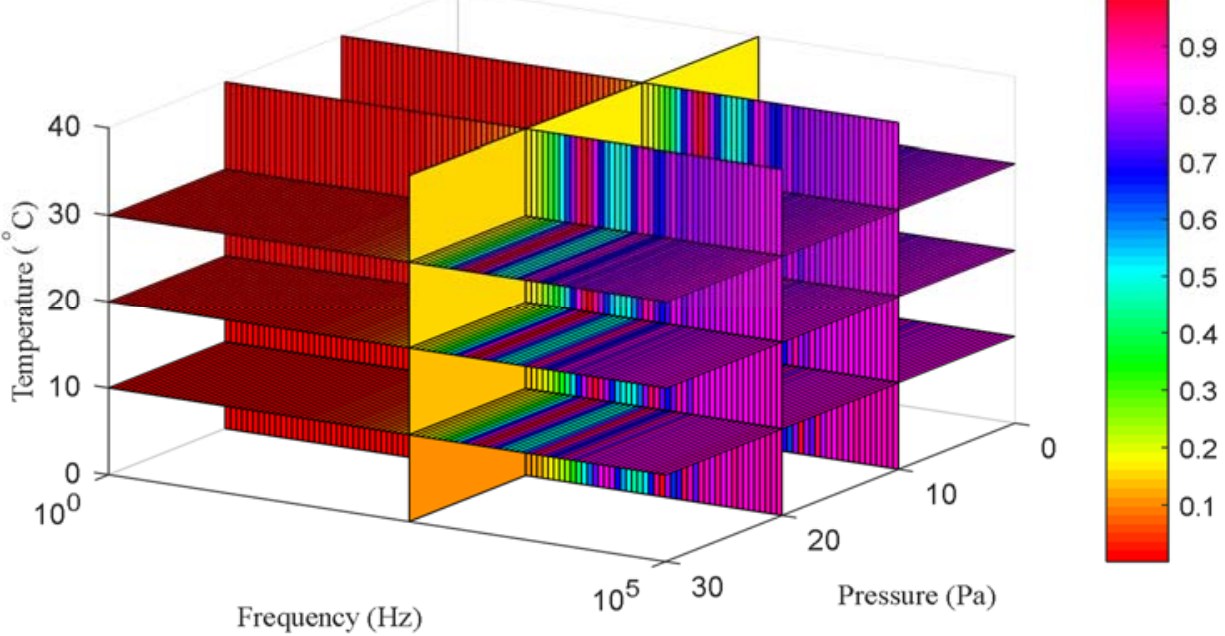

Fig. 12 Prediction of sound absorption at a range of temperature and pressure. (color online)

\section{B. The multiple parameters sensitivity analysis of $\mathrm{H}-\mathrm{N}$ temperature-pressure model}

The sensitivity analysis of environment-independent parameters in $\mathrm{H}-\mathrm{N}$ model is used to investigate the effect of each parameter on mechanical and acoustic responses which leads to a better foundation for structural design of elastomers.

In order to calculate the effect of environment-independent parameters, $\alpha, \beta, E_{0}, E_{\infty}$ on mechanical and acoustic properties, $E^{\prime}, \tan \delta, a$, incremental value of each environmentindependent parameter are successively substituted into $\mathrm{H}-\mathrm{N}$ model by keeping other parameters at their optimized values. Table III shows the range of each environmentindependent parameter. Fourth column in Table III represents the optimized values for each environment-independent parameter.

Next the RMS (root mean square) value of mechanical and acoustic properties are calculated as

$$
\sigma=\sqrt{\sum_{n=1}^{N} x^{2}(n) / N}
$$

where $\mathrm{N}$ represents the total number of frequency points, $x$ represents the response of each 
parameter at corresponding frequency point.

Table III. Environment-independent parameters incremental values

\begin{tabular}{cccccccc}
\hline Parameter & 1 & 2 & 3 & 4 & 5 & 6 & 7 \\
$\alpha$ & 0.336 & 0.386 & 0.436 & 0.486 & 0.536 & 0.586 & 0.636 \\
$\beta$ & 0.489 & 0.539 & 0.589 & 0.639 & 0.689 & 0.739 & 0.789 \\
$E_{0}(\mathrm{~Pa})$ & $1.279 \times 10^{7}$ & $1.779 \times 10^{7}$ & $2.279 \times 10^{7}$ & $2.779 \times 10^{7}$ & $3.279 \times 10^{7}$ & $3.779 \times 10^{7}$ & $4.279 \times 10^{7}$ \\
$E_{\infty}(\mathrm{Pa})$ & $3.494 \times 10^{8}$ & $3.994 \times 10^{8}$ & $4.494 \times 10^{8}$ & $4.994 \times 10^{8}$ & $5.494 \times 10^{8}$ & $5.994 \times 10^{8}$ & $6.494 \times 10^{8}$ \\
\hline
\end{tabular}

The RMS curves for mechanical and acoustic properties are shown in Fig. 13. These curves reflect the change of each mechanical and acoustic property for a range of frequency and environment-independent parameters. As observed from the results, increasing $E_{\infty}, \alpha$ and $\beta$ leads to larger RMS values of absorption parameter, which means better acoustical absorptivity.

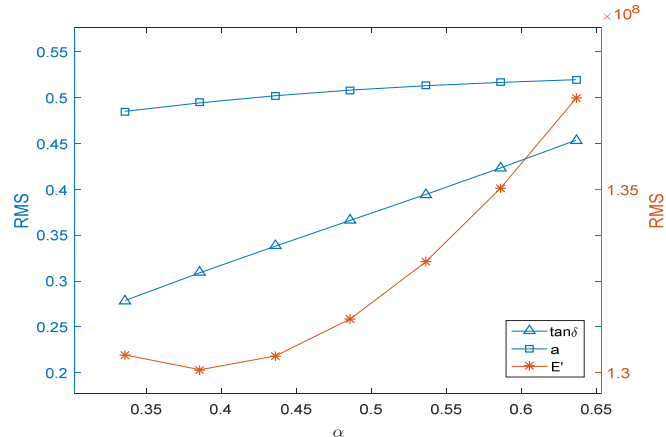

(a)

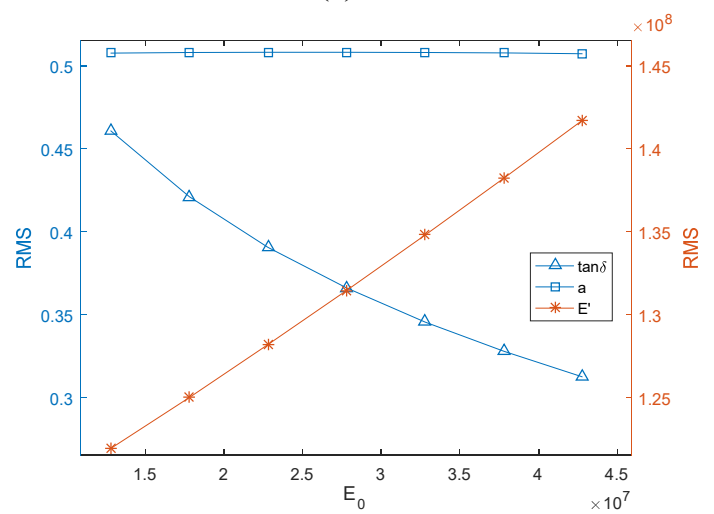

(c)

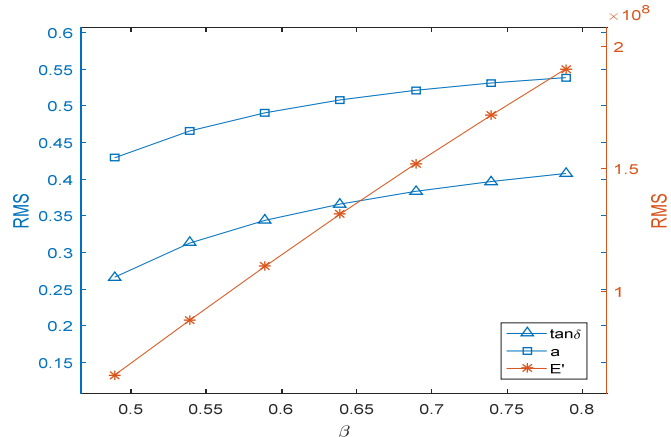

(b)

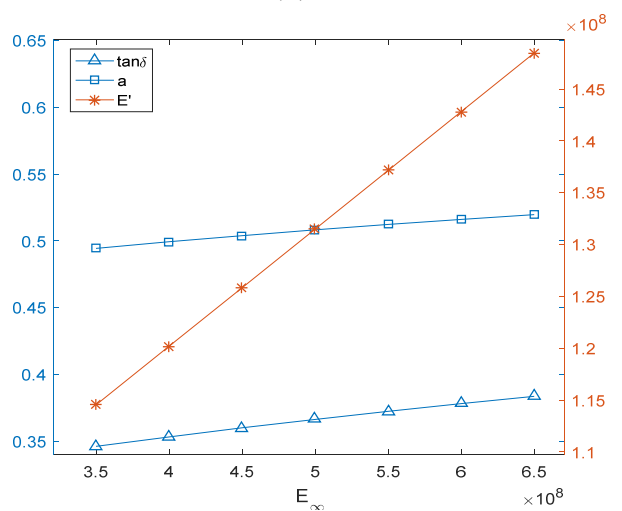

(d)

Fig. 13 Influence of (a) $\alpha$, (b) $\beta$, (c) $E_{0}$ and (d) $E_{\infty}$ to the RMS of each target: storage modulus $E^{\prime}$, loss factor $\tan \delta$ and absorption coefficient $\boldsymbol{a}$.(color online)

Furthermore, sensitivity analysis can be obtained by perturbation method based on the RMS curves.

The sensitivity of each environment-independent parameter to mechanical and acoustic properties can be expressed as

$$
S_{x i}=\left[\sigma\left(B_{i}+\Delta B_{i}\right)-\sigma\left(B_{i}\right)\right] / \Delta B_{i}
$$

where $x$ represents the environment-independent parameter, $B$ represents the mechanical and acoustic property and $i$ represents number of interval $(i=1,2, \cdots, 7)$

The parameter sensitivity for the whole feasible region can be obtained by 


$$
S_{x}=\sqrt{\frac{1}{n} \sum_{i=1}^{n} S_{x i}^{2}}
$$

The environment-independent parameters sensitivity analysis results are shown in Table IV. It is found that the parameter $\beta$ has significant effect on the storage modulus with respect to other parameters. The parameter $\alpha$ has significant effect for the loss factor and absorption coefficient.

Table IV. Sensitivity analysis result of environment-independent Parameters

\begin{tabular}{cccc}
\hline & $\begin{array}{c}\text { Storage Modulus } \\
(\mathrm{Pa})\end{array}$ & Loss Factor & Absorption Coefficient \\
\hline$\alpha$ & 0.027 & 0.579 & 0.124 \\
$\beta$ & 0.418 & 0.488 & 0.102 \\
$E_{0}(\mathrm{~Pa})$ & $6.601 \times 10^{-10}$ & $5.006 \times 10^{-9}$ & $7.168 \times 10^{-11}$ \\
$E_{\infty}(\mathrm{Pa})$ & $1.131 \times 10^{-10}$ & $1.251 \times 10^{-10}$ & $1.847 \times 10^{-10}$ \\
\hline
\end{tabular}

\section{Conclusion}

The main objective of this study is to develop a prediction model for mechanical and acoustic performance of elastomers in different environmental conditions. It specially concerns the improvement of H-N model and WLF shift function. The H-N temperature-pressure model is expressed based on the DMTA data for limited frequency points and single environmental conditions. The absorption parameter is determined by using mechanical properties. The sensitivity analysis for four environment-independent parameters in $\mathrm{H}-\mathrm{N}$ model is constructed for a range of storage modulus, loss factor and absorption coefficient. The predicted results for mechanical and acoustic response concerning different temperatures and pressures are verified by comparing them with experimental data.

As a further investigation on dynamic performance model, active damping behaviour of smart magneto-rheological material which can be utilized for anechoic coating and vibration damping in submarines will be considered.

\section{ACKNOWLEGMENT}

This work was financially supported by National Natural Science Foundation of China (Grants Nos. 11474230 and 11704314), the National Key Research and Development Program of China (Grant No. 2016YFF0200902), the Shaanxi Province Industrial Science and Technology Project (Grant No. 2016GY-111), and the International Cooperation Training Program for the Innovative Talents of China Scholarship Council.

\section{REFERENCES}

${ }^{1}$ J. H. Zhu, Y. S. Wang, Q. Z. Wen and S. R. YAO, "The development and application of underwater acoustic absorption polymer materials," Polymer Materials Science and Engineering. 21, 46(2005).

${ }^{2}$ A. W. Nolle, "Acoustic Determination of the Physical Constants of Rubber-Like Materials," The Journal of the Acoustical Society of America. 19,194-201(1947).

${ }^{3}$ R. Metzler and T. F. Nonnenmacher, "Fractional relaxation processes and fractional rheological models for the description of a class of viscoelastic materials," International Journal of Plasticity. 19, 941-959(2003).

${ }^{4}$ R. Metzler, W. Schick, H. G. Kilian, and T. F. Nonnenmacher, "Relaxation in filled polymers: A fractional calculus approach," The Journal of Chemical Physics. 103, 7180-7186(1995).

${ }^{5}$ K. Diethelm and A. D. Freed. "On the solution of nonlinear fractional-order differential equations used in the 
modeling of viscoplasticity," In Scientific Computing in Chemical Engineering II. Springer, Berlin, Heidelberg, 217-224(1999).

${ }^{6} \mathrm{H}$. Schiessel, R. Metzler, A. Blumen, and T. F. Nonnenmacher, "Generalized viscoelastic models: their fractional equations with solutions," Journal of physics A: Mathematical and General. 28, 6567(1995).

${ }^{7}$ T. G. Mason and D. A. Weitz, "Optical measurements of frequency-dependent linear viscoelastic moduli of complex fluids," Physical review letters. 74, 1250(1995).

${ }^{8} \mathrm{G}$. Huang, B. Wang and $\mathrm{H}$. Lu, "Measurements of viscoelastic functions of polymers in the frequency-domain using nanoindentation," Mechanics of Time-Dependent Materials. 8, 345-364(2004).

${ }^{9} \mathrm{X}$. Li, and B. Bhushan, "A review of nanoindentation continuous stiffness measurement technique and its applications," Materials characterization. 48, 11-36(2004).

${ }^{10}$ E. G. Herbert, W. C. Oliver, A. Lumsdaine and G. M. Pharr, "Measuring the constitutive behavior of viscoelastic solids in the time and frequency domain using flat punch nanoindentation," Journal of Materials Research. 24, 626-637(2009).

${ }^{11} \mathrm{~S}$. Hakimzadeh, "Evaluation of aspects of e* test using hma specimens with varying void contents," (2008).

${ }^{12} \mathrm{~S}$. Havriliak and S. Negami. "A complex plane analysis of $\alpha$-dispersions in some polymer systems." Journal of Polymer Science: Polymer Symposia. 14, 99-117(1966).

${ }^{13}$ T. T. Kararli, J. B. Hurlbut and T. E. Needham, "Glass-rubber transitions of cellulosic polymers by dynamic mechanical analysis," Journal of pharmaceutical sciences. 79, 845-848(1990).

${ }^{14}$ J. P. Szabo, and I. A. Keough, "Method for analysis of dynamic mechanical thermal analysis data using the Havriliak-Negami model," Thermochimica acta. 392, 1-12(2002).

${ }^{15} \mathrm{D}$. Hao and D. Li, "Determination of dynamic mechanical properties of carbon black filled rubbers at wide frequency range using Havriliak-Negami model," European Journal of Mechanics-A/Solids. 53, 303-310(2015).

${ }^{16}$ Y. Sun, J. Chen, and B. Huang, "Characterization of asphalt concrete linear viscoelastic behavior utilizing Havriliak-Negami complex modulus model," Construction and Building Materials. 99, 226-234(2015).

${ }^{17} \mathrm{H}$. Liu and R. Luo. "Development of master curve models complying with linear viscoelastic theory for complex moduli of asphalt mixtures with improved accuracy," Construction and Building Materials. 152, 259-268(2017).

${ }^{18}$ Y. Sun, B. Huang and J. Chen, "A unified procedure for rapidly determining asphalt concrete discrete relaxation and retardation spectra," Construction and Building Materials. 93, 35-48(2015).

${ }^{19} \mathrm{Y}$. Sun, B. Huang, J. Chen, X. Shu and Y. Li, "Characterization of triaxial stress state linear viscoelastic behavior of asphalt concrete," Journal of Materials in Civil Engineering. 29, 04016259(2016).

${ }^{20} \mathrm{~J}$. Feng and Z. Guo, "Effects of temperature and frequency on dynamic mechanical properties of glass/epoxy composites," Journal of materials science. 51, 2747-2758(2016).

${ }^{21}$ D. Hao, L. Zhang, J. Yu and D. Mao, "Mechanical properties of multifunctional structure with viscoelastic components based on FVE model," Acta Astronautica. 143, 255-262(2018).

${ }^{22}$ W. M. Madigosky, G. F. Lee and J. M. Niemiec, "A method for modeling polymer viscoelastic data and the temperature shift function," The Journal of the Acoustical Society of America. 119, 3760-3765(2006).

${ }^{23} \mathrm{R}$. W Chan, "Estimation of viscoelastic shear properties of vocal-fold tissues based on time-temperature superposition," The Journal of the Acoustical Society of America. 110, 1548-1561(2001).

${ }^{24}$ C. Yue-hui, "Acoustics Functional Rubber," Special Purpose Rubber Products. 1, 016(2014).

${ }^{25}$ B.Y. Chen and G. Ma, "Research Progress of High-Dampling RubberSuitable for a Wide Temperature Range," World Rubber Industry. 11, 009(2004).

${ }^{26}$ K. I. Jung, S. W. Yoon, K. Y. Cho and J. Park "Acoustic properties of nitrile butadiene rubber for underwater applications," Journal of applied polymer science. 85, 2764-2771(2002).

${ }^{27}$ B. Hartmann, G. F. Lee, J. D. Lee, J. J. Fedderly and A. E. Berger, "Calculation of relaxation time in polyurethanes using additive group contributions," Journal of applied polymer science. 60, 1985-1993(1996).

${ }^{28}$ A. A. Chuiko, V. S. Sperkach, V. M. Ogenko, T. P. Tantsyura, L. N. Ganyuk, L. V. Dubrovina and A. L. Stribulevich, "Acoustic spectra of some polypropylene glycols. Rotational-isomer relaxation," Polymer Science USSR. 33, 1061-1065(1991).

${ }^{29}$ Y. Dai, J. Yang, "Design and Implement of Water-Filled Test Software Based on Broad Band Pulse Method," Observation and Control Technology. 12:110-113(2014) (in Chinese).

${ }^{30} \mathrm{Y}$. Takahashi, T. Otsuru and R. Tomiku, "In situ measurements of surface impedance and absorption coefficients of porous materials using two microphones and ambient noise," Applied Acoustics. 66, 845-865(2015).

${ }^{31}$ T. Otsuru, N. Okamoto, R. Tomiku, T. Okuzono, and Y. Takahashi. "Impedance measurement of materials by use of ambient noise for computational acoustics." In INTER-NOISE and NOISE-CON Congress and Conference Proceedings. Institute of Noise Control Engineering, 3, 3602-3609 (2006).

${ }^{32} \mathrm{~S}$. Li, R. Miao, "Investigation of Measurement Technique for the Acoustic Properties of Underwater Acoustical Meterials in Free Sound Field," ACTA METROLOGICA SINICA. 4, 12(1999).

${ }^{33} \mathrm{~S}$. Li, R. Miao, "Measurements for the properties of underwater acoustic materials by broadband compressed pulse superposition method," ACTA ACUSTICA-PEKING. 25, 248-253 (2000) 
${ }^{34}$ F. Zhou, J. Fan, "Numerical Water-Filled Tube Application," The Acoustic Society of China. 4, (2015) (in Chinese).

${ }^{35}$ H. Zhao, J. Wen, H. Yang, L. Lv and X. Wen, "Backing effects on the underwater acoustic absorption of a viscoelastic slab with locally resonant scatterers," Applied Acoustics. 76, 48-51(2014).

${ }^{36} \mathrm{P}$. Cervenka and P. Challande, "A new efficient algorithm to compute the exact reflection and transmission factors for plane waves in layered absorbing media (liquids and solids)," The Journal of the Acoustical Society of America. 89, 1579-1589(1991)

${ }^{37}$ E. L. Adler, "Matrix methods applied to acoustic waves in multilayers," IEEE Transactions on Ultrasonics, Ferroelectrics, and Frequency Control. 37, 485-490(1990).

${ }^{38}$ V. G. Jayakumari, R. K. Shamsudeen, R. Ramesh, and T. Mukundan, "Modeling and validation of polyurethane based passive underwater acoustic absorber," The Journal of the Acoustical Society of America. 130, 724730(2011).

39"Damping materials-Graphical presentation of the complex modulus." ISO, 10112(1991).

${ }^{40}$ Ferry J D, "Viscoelastic properties of polymers," New York: Wiley, 1980.Chapt.15, pp.361.

${ }^{41}$ M. L. Williams, "The Temperature Dependence of Relaxation Mechanisms in Amorphous Polymers and Other Glass-forming Liquids," J. Am. Chem. Soc. 77, 3701(1955).

${ }^{42}$ L. Dagdug and L. S. García-Colín, "Generalization of the Williams-Landel-Ferry equation," Physica A: Statistical Mechanics and its Applications. 250, 133-141(1998).

${ }^{43}$ G. U. Losi and W. G. Knauss, "Free volume theory and nonlinear thermoviscoelasticity," Polymer Engineering \& Science. 32, 542-557(1992).

${ }^{44}$ F. M. Guillot and D. H. Trivett, "A dynamic Young's modulus measurement system for highly compliant polymers," The Journal of the Acoustical Society of America. 114, 1334-1345(2003).

${ }^{45}$ P. S. Wilson, R. A. Roy and W. M. Carey, "An improved water-filled impedance tube," The Journal of the Acoustical Society of America. 113, 3245-3252(2003).

46 "Acoustics-Determination of Sound Absorption Coefficient and Impedance in Impedance Tubes-Part 2: Transfer-Function Method." ISO, 10534-10532(1991) 